86

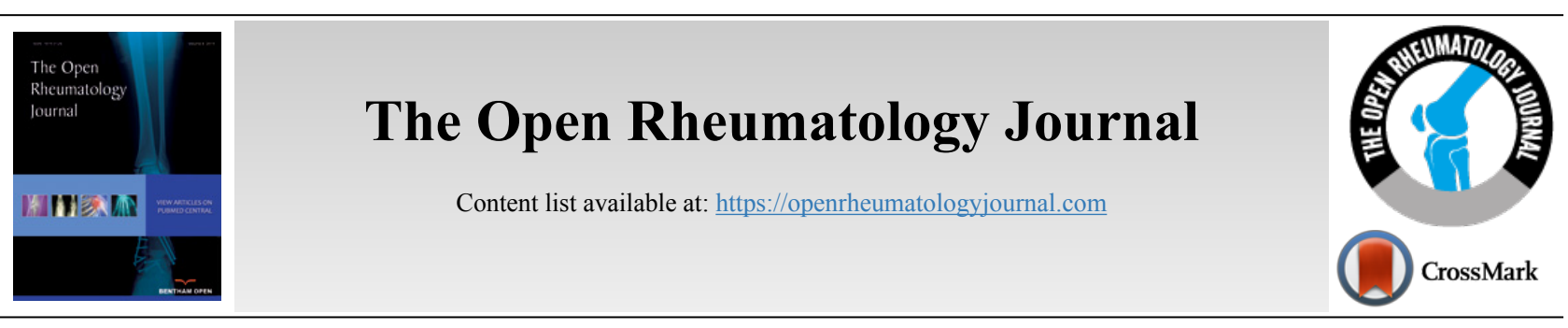

RESEARCH ARTICLE

\title{
Non-Invasive Imaging for Evaluating Cardiovascular Involvement in Patients with Primary and Lupus Nephritis
}

Marco Atteritano ${ }^{1, *}$, Luca Visconti ${ }^{1}$, Giuseppe Dattilo ${ }^{1}$, Carmelo Zuppardo ${ }^{1}$, Antonio Lacquaniti ${ }^{1}$, Vito Maurizio Parato ${ }^{2}$, Alessandro Migliorato ${ }^{1}$, Giovanni Conti ${ }^{3}$ and Domenico Santoro ${ }^{1}$

${ }^{\prime}$ Department of Clinical and Experimental Medicine, University of Messina, Messina, Italy

${ }^{2}$ Department of Emergency, Section of Cardiology, Hospital "Madonna del Soccorso", San Benedetto del Tronto, Italy

${ }^{3}$ Department of Human Pathology in Adulthood and Childhood "G. Barresi”, University of Messina, Messina, Italy

\begin{abstract}
:
Background:

Evidence suggests that proteinuric diseases, such as primary or secondary glomerulonephritis, increase cardiovascular risk, but few studies confirmed this association.

Methods:

This is a cross-sectional, observational study on 32 patients, 17 with Primary Glomerulonephritis (PG) and 15 with Lupus Glomerulonephritis (LG). The control group consisted of 32 healthy individuals. Intima-media thickness (IMT) of the left common carotid artery, carotid bifurcation and internal carotid artery was measured by ultrasound. Left ventricular myocardial deformation was assessed by the use of the Global Circumferential Strain (GCS) and the Global Longitudinal Strain (GLS) following 2-Dimensional (2D) echocardiography in all participants.

Results:

Patients with glomerulonephritis in both groups showed significantly lower GLS compared with controls $(\mathrm{p}=0.0005)$. There was also a significant difference in common carotid IMT values between the LG and GP group $(0.45 \pm 0.09$ vs. $0.58 \pm 0.17 \mathrm{~mm}$, respectively; $\mathrm{p}=0.01)$, but there was no difference with the control group. In patient group $(\mathrm{n}=32)$, a significantly positive correlation was observed between $\mathrm{C}$-reactive protein and proteinuria $(\mathrm{r}=0.98 ; \mathrm{p}<0.0001)$, whereas negative correlations were found between common carotid IMT and creatinine clearance $(\mathrm{r}=-0.97$; $\mathrm{p}<0.0001)$ and between carotid bifurcation IMT and phosphate levels $(\mathrm{r}=-0.97 ; \mathrm{p}<0.0001)$

\section{Conclusion:}

Subclinical systolic myocardial dysfunction is present early in the course of glomerular disease. The use of 2D GLS revealed that LG and PG patients with no cardiovascular symptoms or history and a preserved left ventricle ejection fraction on conventional echocardiography had subclinical reduction in LV global longitudinal systolic function compared with controls.
\end{abstract}

Keywords: Glomerulonephritis, Proteinuria, Lupus nephritis, Echocardiography, Two-dimensional speckle-tracking echocardiography, Atherosclerosis, (PG).

Article History Received: July 23, 2019 Revised: November 28, 2019 Accepted: December 06, 2019

\section{INTRODUCTION}

The prevalence of Chronic Kidney Disease (CKD), estimated between 7 and $12.5 \%$ in the general population [1]. It is increasing worldwide due to the rise in its major causes such as Diabetes Mellitus (DM) and arterial hypertension [2]. CKD

\footnotetext{
* Address correspondence to this author at the Department of Clinical and Experimental Medicine, University of Messina, AOU "Policlinico G. Martino" Via Consolare Valeria n. 1, 98125 Messina, Italy; Tel: +393396753553;

E-mail: marcoatteritano@gmail.com
}

is an independent risk factor for cardiovascular (CV) morbidity and mortality [3 - 5], which occurs early in these patients; CV mortality represents $50-60 \%$ of all-cause mortality in this patient population [6]. Indeed, CKD is considered as Coronary Heart Disease (CHD) equivalent [5]. This association increases with the severity of CKD and is more evident in patients with End-Stage Renal Disease (ESRD) [7, 8]. The presence of traditional $\mathrm{CV}$ risk factors (advanced age, DM, hypertension, dyslipidemia, smoking, obesity, etc) is not 
sufficient to explain the elevated CV morbidity and mortality in CKD [9]. In this context, there are emerging risk factors of this population (such as systemic inflammation, mineral and bone disorders, hyperhomocysteinemia and anemia) that are considered to contribute to their CV risk [10 - 14]. In addition, the presence of albuminuria is associated with $\mathrm{CV}$ disease and it is considered a predictor of all-cause mortality [15]. Proteinuric diseases, such as primary or secondary glomerulonephritis, seem to be correlated with increased CV risk, but few studies confirmed this association. In this context, the risk of $\mathrm{CV}$ events was almost 50 times higher in young women with Systemic Lupus Erythematosus (SLE) compared with the general population of the same gender and age; this finding may be attributed to inflammation and cardiac perfusion changes $[16,17]$. Conventional echocardiographic studies are not able to identify alterations in subclinical CV disease or to discriminate between patients at low and high CV risk. For this reason, it is important to conduct studies evaluating cardiac performance as a marker of early diagnosis of $\mathrm{CV}$ disease. In this context, two-dimensional strain echocardiography (2D-SE) is a rapidly growing technique, validated using sonomicrometry and tagged magnetic resonance imaging, that has been introduced as a valid method to quantify both Left Ventricular (LV) longitudinal and circumferential deformation [18 - 22]. 2D-SE can detect early signs of LV dysfunction, thus improving the ability to quantitatively assess regional LV function [23 - 27].

Another frequent comorbidity in CKD patients is the atherosclerosis of large arteries that have been widely reported in the literature, and in particular in relation to carotid artery remodeling [27]. Of note, the presence of albuminuria is independently associated with an increase in the carotid lumen diameter [28]. There are a few studies that report an association between kidney disease with normal kidney function and atherosclerosis of the large arteries [29].

The aim of the present study was to assess early signs of cardiac dysfunction as well as the presence of carotid atherosclerosis (defined by carotid intima-media thickness) in patients with glomerular diseases.

\section{MATERIALS AND METHODS}

32 consecutive patients were enrolled referred to the Nephrology and Dialysis Unit of the University Hospital "G. Martino" of Messina, for renal biopsy between October 2015 and April 2016 [30]. All patients had a negative history of CV diseases and no evidence of CHD as assessed by ECG and echocardiogram. The control group consisted of 32 healthy volunteers from nurses and physicians working in our hospital, with similar characteristics and a negative clinical history for glomerular, CV disease and CHD (as assessed by history, ECG and echocardiogram). The following factors were considered in the analysis: the presence of comorbidities (DM, hypertension), time since diagnosis of glomerular disease and treatment with vitamin D, immunosuppressants, corticosteroids, lipidlowering agents and antidiabetic drugs. The study was performed in accordance with the Declaration of Helsinki and was approved by the local ethics committee. In only SLE patients, the SLEDAI Score was calculated. The SLEDAI tool is a cumulative and weighted index used to assess disease activity across 24 different disease descriptors in patients with SLE [31,32]. All participants gave their informed consent before entering the study. Inclusion criteria were age $\geq 18$ years, creatinine clearance $\geq 60 \mathrm{ml} / \mathrm{min}$, proteinuria $\geq 300$ $\mathrm{mg} / 24 \mathrm{~h}$ and ejection fraction $\geq 50 \%$. Exclusion criteria were the presence of CKD stage 3-5 or CV disease.

\subsection{Biochemical Measurement}

All participants underwent blood laboratory tests to evaluate the following: hemoglobin, urea, creatinine, calcium, Phosphate, Parathyroid Hormone (PTH), C-reactive protein (CRP) and albumin measured by standard laboratory techniques (Roche-Italy, Monza). Creatinine clearance and daily proteinuria were calculated with $24 \mathrm{~h}$ urine collection [33, 34].

\subsection{Echocardiographic Measurements}

Two-dimensional echocardiographic images were acquired using ultrasound equipment (My Lab ALFA, Esaote, Florence, Italy) with a $2.5-\mathrm{MHz}$ phased-array transducer. $2 \mathrm{D}$ data were obtained with parasternal long- and short-axis views and the three standard apical views according to the recommendations of the American Society for Echocardiography for the analysis of wall motion, End-Diastolic Volume (EDV), End-Systolic Volume (ESV) and Ejection Fraction (EF). The procedure was performed by the same, blinded, operator (G.D.)

\subsection{Speckle-tracking Analysis by 2D Echocardiography}

A dedicated software package (XStrain ${ }^{\mathrm{TM}}$, Esaote, Florence, Italy), was used for an "off-line" quantification of circumferential (Fig. 1A) and longitudinal (Fig. 1B) strain.

The LV was divided according to the 16-segment model (6 basal, 6 mid-level, and 4 apical). Short-axis views images, obtained at the mitral valve, papillary muscles and apical levels, were used to compute circumferential strain. The longitudinal strain was calculated using standard apical 4-, 3-, and 2-chamber views. Global Strain (GS) was defined as the mean value of 16 segments. In all patients, we calculated Global Circumferential Strain (GCS) and the Global Longitudinal Strain (GLS). The procedure was performed by the same, blinded, operator (G.D.).

\subsection{Carotid Intima Media Thickness (cIMT)}

cIMT was measured by a high-resolution MyLab 70 scanner (Esaote) with the use of a linear and high frequency (7-12 MHz) transducer. These data were calculated on the left side of the common carotid artery, common carotid artery bifurcation and internal carotid artery. The procedure was performed by the same, blinded, operator (G.D).

\subsection{Statistical Analysis}

Statistical analyses were performed using the Statistica software package (release 4.5; StatSoft, Tulsa, OK, USA). Values are expressed as mean $\pm \mathrm{SD}$ or percentage. The normality of distribution of continuous variables was assessed by the Kolmogorov-Smirnov test. Comparisons between groups were performed by Student's t-test. The percentage of each variable was compared between groups by Fisher's exact test. Pearson's correlation coefficient was used to evaluate correlations. Values of a 2 -sided $\mathrm{p}<0.05$ were considered as significant. 


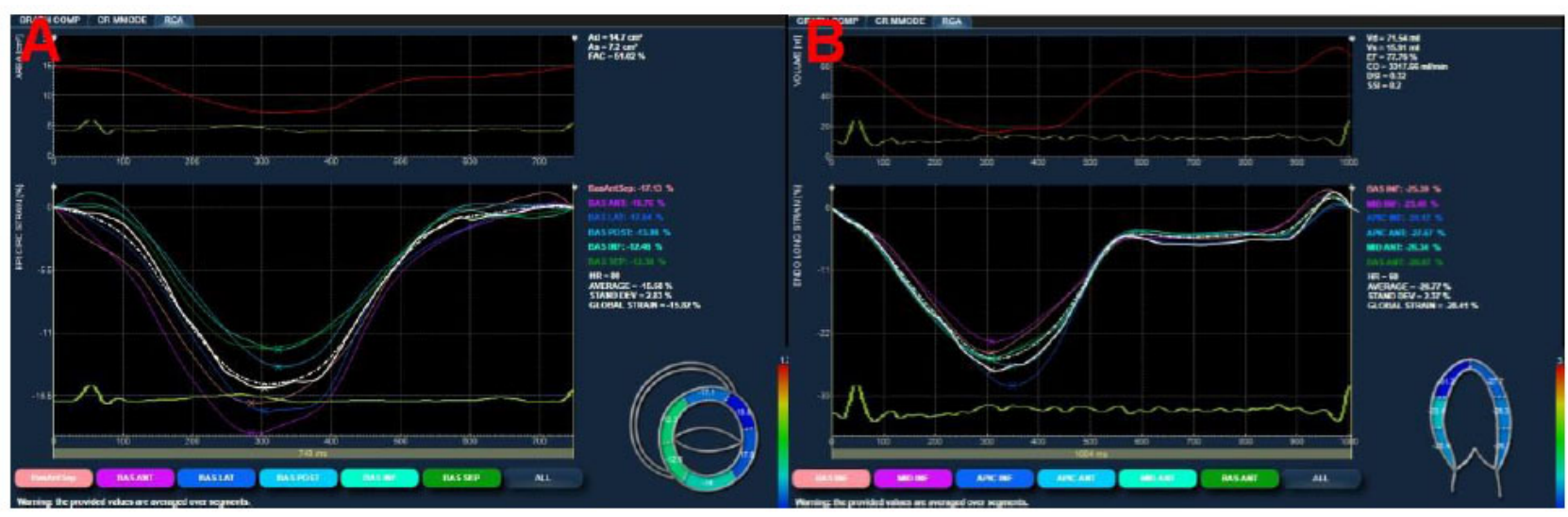

Fig. (1). 2D acquisitions for the "off-line" evaluation of Strain. Panel A: Evaluation of Circumferential Strain. Panel B: Evaluation of Longitudinal Strain.

\section{RESULTS}

The study included 32 patients (18 female) with a mean age of $41 \pm 4.2$ years. Overall, 15 of these patients were affected by lupus glomerulonephritis (LG group) and 17 by primary glomerulonephritis (PG group), consisting of IgA nephropathy $(\operatorname{IgAN})(\mathrm{n}=7)$, membranous glomerulonephritis $(\mathrm{MGN})(\mathrm{n}=5)$, minimal change nephropathy $(\mathrm{MCN})(\mathrm{n}=4)$ and focal and segmental glomerulosclerosis (FSGS) $(n=1)$. Clinical characteristics of lupus glomerulonephritis patients, primary glomerulonephritis patients and control group are shown in Table 1. Duration of disease was 80.46 months in the LG group and 43.05 in the PG group $(\mathrm{p}=0.017)$. Hypertension was present in 53.2 and $94.1 \%$ of the patients in the LG and PG group, respectively $(\mathrm{p}=0.006)$. DM was present in 13.3 and $11.8 \%$ of the patients in the LG and PG group, respectively $(p=0.89)$. In the PG group, a higher percentage of patients were treated with vitamin $\mathrm{D}$ and a lower percentage with steroid and immunosuppressive drugs compared with the LG group. The control group was not on any medication. The SLEDAI score in the LG group was $8.26 \pm 3.99$. The mean creatinine clearance was similar in the LG and PG groups $(102 \pm 30 v s 99 \pm 39$ $\mathrm{ml} / \mathrm{min} ; \mathrm{p}=0.8)$ and in the control group $105 \pm 35(\mathrm{p}=0.57 v \mathrm{~s}$ $\mathrm{PG} ; \mathrm{p}=0.76$ vs LG). The patients' groups have $24 \mathrm{~h}$ proteinuria statistically significantly higher than that of the control group. (Table 1).

Serum levels of calcium (Ca) and phosphorus (P) did not differ significantly between the study groups.

Plasma levels of PTH were significantly higher in patients groups than the control group $(46.7 \mathrm{pg} / \mathrm{ml}$ in the LG group, $41,69 \pm 23,07 \mathrm{pg} / \mathrm{ml}$ in the PG group and $28.8 \mathrm{pg} / \mathrm{ml}$ in the control) ( $\mathrm{p}=0.005 \mathrm{LG}$ vs control and $\mathrm{p}=0.03 \mathrm{PG}$ vs control).

Table.2 reports the Echocardiographic and vascular parameters in all three groups. Myocardial function, assessed by conventional echocardiography, showed normal left ventricular (LV) systolic function in all groups. Furthermore, there were no significant differences in relation to wall motion, EDV, ESV and EF between all groups. In speckle-tracking analysis, GLS was significantly lower in the LG and PG groups compared with the control group (LG group vs controls: 20.06 \pm 2.60 vs $22.7 \pm 2.10 ; \mathrm{p}=0.0005$, PG group $v s$ controls: 20.23 \pm 2.77 vs $22.7 \pm 2.10 ; \mathrm{p}=0.001)$. With regard to the GCS, there were no significant differences between groups (Table 2).

Common cIMT was significantly higher in the PG compared with the $\mathrm{LG}$ group (i.e. $0.58 \pm 0.17$ vs $0.45 \pm 0.09$ $\mathrm{mm}$, respectively; $\mathrm{p}=0.01$ ). In contrast, carotid bifurcation IMT and internal cIMT did not differ between LG and PG groups $(0.74 \pm 0.42 v s 0.84 \pm 0.47 \mathrm{~mm} ; \mathrm{p}=0.53$ and $0.50 \pm$ 0.24 vs $0.54 \pm 0.20 \mathrm{~mm} ; \mathrm{p}=0.60$, respectively). Compared with the control group, no significant differences in cIMT values were observed overall. In all patients $(n=32)$, a positive correlation was found between CRP and proteinuria $(r=0.98$; $\mathrm{p}<0.05$ ), whereas there were negative correlations between common cIMT and creatinine clearance $(r=-0.97 ; p<0.05)$ and between carotid bifurcation IMT and phosphate levels ( $\mathrm{r}=$ $-0.97 ; \mathrm{p}<0.05)$.

\section{DISCUSSION}

The present study shows that subclinical myocardial dysfunction (assessed by GS) may be present in patients with primary or secondary glomerulonephritis. To the best of our knowledge, this is the first study to evaluate the potential CV risk of these patients by speckle-tracking analysis.

Several studies demonstrated that CKD is an independent risk factor for $\mathrm{CV}$ disease; this risk increases even in the early stages of CKD i.e. when estimated glomerular filtration rate (eGFR) levels are $>60 \mathrm{ml} / \mathrm{min} / 1.73 \mathrm{~m}^{2}[33,34]$.

There is increasing evidence that structural myocardial changes and subclinical cardiac dysfunction may present early in the course of CKD (Table 3). These abnormalities in cardiac structure may worsen with $\mathrm{CKD}$ progression without significant changes in systolic or diastolic function [35 - 31]. The prevalence of cardiac dysfunction is represented primarily by $\mathrm{LV}$ hypertrophy $(\mathrm{LVH})$, reported in $40-78 \%$ of CKD patients and $74 \%$ of ESRD patients [38]. Unfortunately, conventional echocardiography cannot identify subclinical systolic and diastolic dysfunction, since the global cardiac function is preserved at the early stages of cardiac disease [20, $23,39]$. 
Table 1. Clinical characteristics of lupus glomerulonephritis patients, primary glomerulonephritis patients and control group. Results are expressed as number, means \pm S.D., percentage and median (range).

\begin{tabular}{|c|c|c|c|}
\hline- & LG Group (n=15) & PG Group (n=17) & Control Group (n=32) \\
\hline Mean age (years) & $39.0 \pm 12.7$ & $43.3 \pm 14.8$ & $40.4 \pm 10.4$ \\
\hline Sex, M/F n & $2 / 13$ & $12 / 5$ & $13 / 19$ \\
\hline Months of diagnosis & 80.5 & $43.0 *$ & NA \\
\hline Diabetes (n, \%) & $2(13.3 \%)$ & $2(11.8 \%)^{*}$ & 0 \\
\hline Hypertension (n, \%) & $8(53.2 \%)$ & $16(94.1 \%)^{*}$ & 0 \\
\hline Dyslipidemia (n, \%) & $2(13.3 \%)$ & $5(29.4 \%)$ & $131.4 \pm 30.8$ \\
\hline C3 (mg/dl) & $110.3 \pm 27.5$ & $125.3 \pm 32$ & $28(16-40)$ \\
\hline C4 (mg/dl) & $23(14-37)$ & $34(22-38.5)$ & $0.9(0.1-1.8)$ \\
\hline CRP (mg/dl) & $1(0.1-3.4)$ & $0.6(0.1-1.2)$ & $4.5 \pm 0.2$ \\
\hline Albumin (g/dL) & $3.92 \pm 0.6$ & $4.0 \pm 0.6$ & $156 \pm 24 \S$ \\
\hline 24 Proteinuria (mg) & $914 \pm 1719$ & $1109 \pm 1850$ & $105.3 \pm 16.2$ \\
\hline Creatinine clearance (ml/min) & $102.2 \pm 30.3$ & $99.1 \pm 38.8$ & $9.6 \pm 0.5$ \\
\hline Ca (mg/dl) & $9.1 \pm 0.5$ & $9.4 \pm 0.7$ & $3.2 \pm 0.9$ \\
\hline P (mg/dl) & $3.5 \pm 0.8$ & $3.3 \pm 0.7$ & $30.7(23-47)$ \\
\hline PTH (pg/ml) & $36.3(28-67)$ & $40.1(31-43.9)$ & 0 \\
\hline Vitamin D therapy (n, \%) & $8(53.3 \%)$ & $11(68.7 \%)$ & NA \\
\hline Steroid therapy (months) & $48(39-120)$ & $20(7-42)$ & NA \\
\hline Total glucocorticoid cumulative dose, $(\mathrm{g})$ & $9.06 \pm 4.09$ & $5.2 \pm 2.3$ & NA \\
\hline Immunosuppressive therapy (months) & $47(33-88)$ & $8(3-26)$ & NA \\
\hline SLEDAI-2K & $8.26 \pm 3.99$ & NA & \\
\hline
\end{tabular}

LG: lupus glomerulonephritis; PG: primary glomerulonephritis; C3: serum complement C3; C4: serum complement C4; CRP: C-reactive protein; PTH: Parathyroid Hormone; Ca: Calcium; P: Phosphorus; SLEDAI-2K: Systemic Lupus Erythematosus Disease Activity Index. NA: Not applicable. *p<0.05 LG $v s$ PG; §: p<0.001 Control vs LG and PG.

Table 2. Echocardiographic and vascular parameters expressed as mean \pm SD.

\begin{tabular}{|c|c|c|c|}
\hline- & LG Group & PG Group & Control Group \\
\hline IMT CC (mm) & $0.45 \pm 0.09$ & $0.58 \pm 0.17^{\circ}$ & $0.44 \pm 0.15$ \\
\hline IMT bifurcation (mm) & $0.74 \pm 0.42$ & $0.84 \pm 0.47$ & $0.72 \pm 0.35$ \\
\hline IMT IC (mm) & $0.50 \pm 0.24$ & $0.54 \pm 0.20$ & $0.48 \pm 0.15$ \\
\hline Longitudinal strain (\%) & $20.06 \pm 2.60^{*}$ & $20.23 \pm 2.77^{\S}$ & $22.7 \pm 2.10$ \\
\hline Circumferential strain (\%) & $26.53 \pm 2.50$ & $26.05 \pm 3.40$ & $26.3 \pm 2.76$ \\
\hline
\end{tabular}

IMT CC: intima-media thickness of the common carotid artery - IMT IC: intima-media thickness of the internal carotid artery - LG: lupus glomerulonephritis patients PG: primary glomerulonephritis patients $-{ }^{\circ} \mathbf{p}=0.01 \mathrm{PG}$ vs LG; * $\mathbf{p}=0.0005$ LG vs Control Group; $\$ \mathbf{p}=0.001$ PG vs Control Group

Table 3. Prevalence of myocardial abnormalities in chronic kidney disease and systemic lupus erythematosus patients evaluated by conventional echocardiography and 2D speckle-tracking echocardiography.

\begin{tabular}{|c|c|c|c|c|}
\hline Authors & Date of publication & Population & Diagnostic tool & Myocardial abnormalities \\
\hline Foley et al. [32] & 1995 & 433 ESRD patients & Echocardiography & $73.9 \%$ LVH \\
& & & & $35.5 \%$ LVD \\
& & & & $14.8 \%$ SD \\
\hline Park et al. [31] & 2012 & 3,487 CKD patients & Echocardiography & $50 \%$ LVH \\
& & & & $13 \%$ LVD \\
& & & & $8 \%$ SD \\
\hline Liu et al. [41] & 2011 & 153 CKD patients & 2D speckle-tracking echocardiography & Reduced GLS \\
\hline Dai et al. [23] & 2016 & 60 SLE patients & 2D speckle-tracking echocardiography & Reduced GLS \\
\hline Leal et al. [15] & 2015 & 35 SLE patients & 2D speckle-tracking echocardiography & Reduced GLS \\
\hline
\end{tabular}

CKD: chronic kidney disease; SLE: systemic lupus erythematosus; LVH: left ventricular hypertrophy; LVD: left ventricular dilatation; SD: systolic dysfunction; GLS global longitudinal strain

Quantification of myocardial strain, a measure of cardiac abnormalities, can be useful in identifying subclinical changes in LV function. Two-dimensional speckle tracking echocardiography (2D-SE) is a relatively new echocardiographic technique that evaluates regional LV function. The purpose of this technique is to analyze 
myocardial deformities by tracking natural acoustic reflections and interference patterns, validated with measurements obtained by sonomicrometry and magnetic resonance imaging. Several studies demonstrated that cardiac strain assessment may detect early deterioration of cardiac function [40, 41]. In a study performing 2D-SE, GLS was significantly higher in the control group ( $\mathrm{n}=30$ healthy individuals) compared with the hypertensive group $(n=60$ hypertensive patients, aged $<50$ years) with preserved LVEF; EF did not significantly differ between the two groups [42]. The observed reduced GLS in the hypertensive group was interpreted as systolic dysfunction, thus demonstrating that this technique may be able to detect subclinical myocardial dysfunction [42].

Cardiac strain assessment is also useful to evaluate the potential risk for concentric hypertrophy as well as $\mathrm{CV}$ mortality and hospitalization due to heart failure, Myocardial Infarction (MI) and stroke [43 - 45]. In this context, in a study of 388 asymptomatic patients with hypertensive heart disease, followed for Major Adverse Cardiac Events (MACE) over a median of 4 years, a lower GLS at baseline was associated with a higher risk of MACE [46]. Furthermore, the presence of cardiac strain may detect subclinical LV dysfunction in CKD patients. Indeed, GLS was significantly lower in CKD patients (37 with moderate-advanced CKD and 60 with ESRD undergoing maintenance hemodialysis) compared with 56 controls, without any differences in EF between groups, confirming that reduced renal function was associated with systolic dysfunction [47]. In another study of 447 CKD patients, a lower GLS was an important predictor of all-cause mortality [48]. Similarly, in the present study, it has been demonstrated that patients with primary and secondary glomerulonephritis had a significantly lower GLS compared with controls, thus supporting the increased CV risk in these patients. Of note, SLE patients have an increased rate of CV events, as reported in a systematic review showing that $\mathrm{CV}$ risk is at least doubled in these patients compared with the general population [49]. CV risk factors included not only traditional ones but also disease duration and activity, as well as glucocorticoid use [49].

Despite the awareness of the increased CV risk in SLE patients, hospitalizations for acute MI or stroke in these patients are still frequent [50]. The pathophysiological mechanisms involved are not completely understood, with a mixture of traditional (hyperlipidemia, DM, smoking, hypertension, obesity) and non-traditional risk factors (disease activity, duration, and therapy), with chronic inflammation playing a causative role $[12,51,52]$. Conversely, there are only a few data about CV risk in patients with PG. A recent study demonstrated that patients with primary membranous nephropathy had an increased CV risk early in the course of their disease [53]. Briefly, 404 such patients were followed for a median of 24.3 months; 31 patients experienced a CV event (22 were acute coronary syndromes, 8 acute ischemic cerebrovascular events and 1 acute peripheral arterial thromboembolic event) [53]. Our study confirms that both populations (i.e. those with LG and PG) are at an increased risk for cardiac disease.

Atherosclerosis, evaluated by cIMT, is a frequent complication of CKD [54]. In a study comparing 95 CKD patients with 121 hypertensive patients (without CKD) and 57 normotensive individuals, CKD patients had a significantly greater carotid internal diameter (common carotid artery) than hypertensives and normotensives, resulting in 25 and $11 \%$ increases in circumferential wall stress, respectively; no significant differences were observed in cIMT [55]. Patients with SLE also have an increased prevalence of atherosclerosis [56]. In this context, Roman et al. showed that atherosclerosis, assessed by the presence of plaques, IMT values and diameter of common carotid arteries, was more prevalent in SLE patients compared with controls (37.1 vs 15.2\%, p <0.001), indicating that SLE may be an independent risk factor for atherosclerosis [57]. Furthermore, in another study, stroke incidence was increased in SLE patients compared with the general population [58].

Conversely, there are only a few data on carotid abnormalities in patients with glomerular disease and preserved renal function. Iannuzzi et al. compared 30 patients with glomerular disease and GFR $>30 \mathrm{ml} / \mathrm{min} / 1.73 \mathrm{~m}^{2} v s 30$ controls [59]. Atherosclerosis was evaluated by carotid artery diameter, IMT and stiffness. The results showed that all these markers were greater in patients with glomerular disease compared with controls [59]. In our study, common cIMT was significantly higher in the PG compared with the LG group, but there were no significant differences between the two patient groups and the control group. These data suggest an increased risk for atherosclerosis development in PG patients with normal renal function (i.e. normal creatinine clearance), underlining the need for an early $\mathrm{CV}$ assessment and treatment in these patients. Serum CRP levels were also significantly associated with proteinuria in both groups. This correlation suggests that lowgrade inflammation may play a role in the development and progression of proteinuria. Several studies showed that inflammation is correlated with endothelial dysfunction as responsible for proteinuria and increased $\mathrm{CV}$ risk.

The results from the present study suggest that patients with glomerulonephritis have a high $\mathrm{CV}$ risk. Thus, $\mathrm{CV}$ risk should be assessed in such patients and modifiable CV risk factors should be aggressively addressed. In this context, it is important to detect early cardiac alterations and initiate treatment to reduce $\mathrm{CV}$ morbidity and mortality. Some drugs used in CV diseases have a renoprotective effect. Statins may exhibit significant renoprotective effects beyond their lipidlowering capacity [60 - 62].

In this context, statins can exert anti-inflammatory actions in the renal tissue, prevent renal scarring and diminish mesangial or other kidney cell-type proliferation while promoting mesangial cell apoptosis [63]. CKD is a risk factor for accelerated atherosclerosis; statin therapy should be initiated with a low-density lipoprotein target of $<100 \mathrm{mg} / \mathrm{dL}$ (when eGFR $=30-59 \mathrm{~mL} / \mathrm{min} / 1.73 \mathrm{~m}^{2}$ ) or $<70 \mathrm{mg} / \mathrm{dL}$ (when eGFR $<30 \mathrm{~mL} / \mathrm{min} / 1.73 \mathrm{~m}^{2}$ ) [62]. Of note, statins can also prevent acute kidney injury following contrast media administration [64 - 69].

Several studies confirmed the renoprotective effect of angiotensin-converting enzyme inhibitors (ACE-Is) and angiotensin receptor blockers (ARBs); ACE-Is and ARBs can reduce microalbuminuria and proteinuria, preserve kidney function and delay end-stage renal disease [70]. The activation of the Renin-Angiotensin-Aldosterone System (RAAS) plays a 
key role in the development and progression of CV disease, especially in arterial hypertension, heart failure and coronary artery disease. ACE-Is exert neurohormonal modulatory effects, such as vasodilatory, anti-inflammatory, plaquestabilizing, antithrombotic and anti-proliferative effects. ARBs have similar pharmacological properties to ACE-Is [71]. According to guidelines [65], if proteinuria is $\geq 0.5 \mathrm{~g} / 24 \mathrm{~h}$, ACEIs or ARBs should be administered and blood pressure should be maintained $\leq 130 / 80 \mathrm{mmHg}$ [72]. In lupus nephritis, corticosteroid therapy should be instituted in cases of clinically significant renal disease [65].

Immunosuppressive agents, particularly cyclophosphamide, azathioprine, or mycophenolate mofetil, should be administered in the presence of aggressive proliferative renal lesions, as they may improve renal outcomes. Immunosuppressive drugs can also be used in patients with an inadequate response or excessive sensitivity to corticosteroids $[65,73,74]$. Current treatment for glomerulonephritis is non-specific; immunosuppression is effective for immune-mediated diseases but may frequently lead to complications related to medication toxicities. It is possible that patients are genetically predisposed to have a better response to certain therapies. Precision medicine, combining modern technologies with molecular and genetic information to identify mechanisms of diseases for targeted treatment and disease prevention, may be coming of age in nephrology [75].

The main limitation of the present study is the small sample size. On the other hand, the strengths of the study are the duration of the follow-up and the absence of evident CV disease. Indeed, this population has been considered at a high risk of CV disease, but it was not possible to demonstrate this at an early stage.

\section{CONCLUSION}

The present study shows that patients with glomerular diseases, even with normal creatinine clearance, are at high risk for $\mathrm{CV}$ disease, independently from traditional risk factors. Subclinical atherosclerosis may occur early in the course of these diseases. In this context, LVEF measurements are not useful for an earlier diagnosis of LV dysfunction, whereas GS may be used to assess subclinical cardiac alterations. Furthermore, common cIMT was higher in the PG group compared with the LG group, thus representing a potential risk factor for atherosclerosis development.

\section{AUTHORS' CONTRIBUTION}

All authors contributed to: (1) substantial conception, design, acquisition of data, analysis and interpretation of data, (2) drafting of the article or revising it critically for important intellectual content, and, (3) final approval of the version to be published.

\section{ETHICS APPROVAL AND CONSENT TO PARTI- CIPATE}

The study is approved by the local ethics committee of University of Messina, Italy.

\section{HUMAN AND ANIMAL RIGHTS}

No animals were used in this research. All human research procedures were followed in accordance with the ethical standards of the committee responsible for human experimentation (institutional and national), and with the Helsinki Declaration of 1975, as revised in 2013.

\section{CONSENT FOR PUBLICATION}

Written informed consent was obtained from all the participants when they were enrolled.

\section{AVAILABILITY OF DATA AND MATERIALS}

The authors confirm that the data supporting the findings of this research are available within the article.

\section{FUNDING}

None.

\section{CONFLICT OF INTEREST}

The authors declare no conflict of interest, financial or otherwise.

\section{ACKNOWLEDGEMENTS}

Declared none.

\section{REFERENCES}

[1] Trifirò G, Sultana J, Giorgianni F, et al. Chronic kidney disease requiring healthcare services: A new approach to evaluate epidemiology of renal disease. BioMed Res Int 2014; 2014268362 [http://dx.doi.org/10.1155/2014/268362] [PMID: 25506054]

[2] Cowie CC, Rust KF, Byrd-Holt DD, et al. Prevalence of diabetes and impaired fasting glucose in adults in the U.S. population: National Health And Nutrition Examination Survey 1999-2002. Diabetes Care 2006; 29(6): 1263-8.

[http://dx.doi.org/10.2337/dc06-0062] [PMID: 16732006]

[3] Go AS, Chertow GM, Fan D, McCulloch CE, Hsu CY. Chronic kidney disease and the risks of death, cardiovascular events, and hospitalization. N Engl J Med 2004; 351(13): 1296-305. [http://dx.doi.org/10.1056/NEJMoa041031] [PMID: 15385656]

[4] K/DOQI clinical practice guidelines for chronic kidney disease: Evaluation, classification, and stratification. Am J Kidney Dis 2002; 39(2)(Suppl. 1): S1-S266. [PMID: 11904577]

[5] Athyros VG, Katsiki N, Karagiannis A, Mikhailidis DP. Editorial: Should chronic kidney disease be considered as a coronary heart disease equivalent? Curr Vasc Pharmacol 2012; 10(3): 374-7. [http://dx.doi.org/10.2174/157016112799959422] [PMID: 22272896]

[6] Sharples EJ, Pereira D, Summers S, et al. Coronary artery calcification measured with electron-beam computerized tomography correlates poorly with coronary artery angiography in dialysis patients. Am J Kidney Dis 2004; 43(2): 313-9.

[http://dx.doi.org/10.1053/j.ajkd.2003.10.035] [PMID: 14750097]

[7] Hage FG, Venkataraman R, Zoghbi GJ, Perry GJ, DeMattos AM, Iskandrian AE. The scope of coronary heart disease in patients with chronic kidney disease. J Am Coll Cardiol 2009; 53(23): 2129-40. [http://dx.doi.org/10.1016/j.jacc.2009.02.047] [PMID: 19497438]

[8] Athyros VG, Katsiki N, Karagiannis A, Mikhailidis DP. Stage of chronic kidney disease and severity of coronary heart disease manifestation. Expert Opin Pharmacother 2012; 13(4): 457-60. [http://dx.doi.org/10.1517/14656566.2012.661716] [PMID: 22332967]

[9] Visconti L, Benvenga S, Lacquaniti A, et al. Lipid disorders in patients with renal failure: Role in cardiovascular events and progression of chronic kidney disease. J Clin Transl Endocrinol 2016; 6: 8-14.

[http://dx.doi.org/10.1016/j.jcte.2016.08.002] [PMID: 29067238]

[10] Sud M, Naimark DM. Cardiovascular disease in chronic kidney 
disease in 2015. Curr Opin Nephrol Hypertens 2016; 25(3): 203-7. [http://dx.doi.org/10.1097/MNH.0000000000000213]

[PMID: 27023835]

[11] Imbalzano E, Casale M, D'Angelo M, et al. Cardiovascular risk and psoriasis: A role in clinical cardiology? Angiology 2015; 66(2): 101-3. [http://dx.doi.org/10.1177/0003319714527339] [PMID: 24671131]

[12] Dattilo G, Borgia F, Guarneri C, et al. Cardiovascular Risk in Psoriasis: Current State of the Art. Curr Vasc Pharmacol 2017. Epub ahead of print

[http://dx.doi.org/10.2174/1570161115666171116163816] [PMID: 29149819]

[13] Atteritano M, Di Mauro E, Canale V, et al. Higher serum sclerostin levels and insufficiency of vitamin D are strongly associated with vertebral fractures in hemodialysis patients: a case control study. Osteoporos Int 2017; 28(2): 577-84.

[http://dx.doi.org/10.1007/s00198-016-3770-9] [PMID: 27682249]

[14] Crisafulli A, Romeo A, Floccari F, et al. Osteoprotegerin and bone mineral density in hemodiafiltration patients. Ren Fail 2005; 27(5): 531-9.

[http://dx.doi.org/10.1080/08860220500198698] [PMID: 16152990]

[15] Xia F, Liu G, Shi Y, Zhang Y. Impact of microalbuminuria on incident coronary heart disease, cardiovascular and all-cause mortality: A metaanalysis of prospective studies. Int J Clin Exp Med 2015; 8(1): 1-9. [PMID: 25784968]

[16] Knight JS, Kaplan MJ. Cardiovascular disease in lupus: Insights and updates. Curr Opin Rheumatol 2013; 25(5): 597-605. [http://dx.doi.org/10.1097/BOR.0b013e328363eba3] 23846339]

[PMID:

[17] Leal GN, Silva KF, França CM, et al. Subclinical right ventricle systolic dysfunction in childhood-onset systemic lupus erythematosus: Insights from two-dimensional speckle-tracking echocardiography. Lupus 2015 ; 24(6): 613-20.

[http://dx.doi.org/10.1177/0961203314563135] [PMID: 25492941]

[18] Korinek J, Wang J, Sengupta PP, et al. Two-dimensional strain-a Doppler-independent ultrasound method for quantitation of regional deformation: Validation in vitro and in vivo. J Am Soc Echocardiogr 2005; 18(12): 1247-53.

[http://dx.doi.org/10.1016/j.echo.2005.03.024] [PMID: 16376750]

[19] Amundsen BH, Helle-Valle T, Edvardsen T, et al. Noninvasive myocardial strain measurement by speckle tracking echocardiography: Validation against sonomicrometry and tagged magnetic resonance imaging. J Am Coll Cardiol 2006; 47(4): 789-93.

[http://dx.doi.org/10.1016/j.jacc.2005.10.040] [PMID: 16487846]

[20] Dattilo G, Imbalzano E, Lamari A, et al. Ischemic heart disease and early diagnosis. Study on the predictive value of $2 \mathrm{D}$ strain. Int $\mathrm{J}$ Cardiol 2016; 215: 150-6.

[http://dx.doi.org/10.1016/j.ijcard.2016.04.035] [PMID: 27111182]

[21] Dattilo G, Lamari A, Zito C, Carerj S, Marte F, Patanè S. 2Dimensional strain echocardiography and early detection of myocardial ischemia. Int $\mathrm{J}$ Cardiol 2010; 145(1): e6-8. [http://dx.doi.org/10.1016/j.ijcard.2008.12.100] [PMID: 19185369]

[22] Edvardsen T, Helle-Valle T, Smiseth OA. Systolic dysfunction in heart failure with normal ejection fraction: Speckle-tracking echocardiography. Prog Cardiovasc Dis 2006; 49(3): 207-14. [http://dx.doi.org/10.1016/j.pcad.2006.08.008] [PMID: 17084180]

[23] Dattilo G, Imbalzano E, Casale M, et al. Psoriasis and cardiovascular risk: Correlation between psoriasis and cardiovascular functional indices. Angiology 2018; 69(1): 31-7.

[http://dx.doi.org/10.1177/0003319717699329] [PMID: 29212353]

[24] Imbalzano E, Di Bella G, Lamari A, et al. Right ventricular myocardial deformation in young healthy subjects: A comparison study between 2D Strain and traditional parameters. Exp Clin Cardiol 2014; 20: 2729-43.

[25] de Gregorio C, Dattilo G, Casale M, Terrizzi A, Donato R, Di Bella G. Left atrial morphology, size and function in patients with transthyretin cardiac amyloidosis and primary hypertrophic cardiomyopathycomparative strain imaging study. Circ J 2016; 80(8): 1830-7. [http://dx.doi.org/10.1253/circj.CJ-16-0364] [PMID: 27350016]

[26] Dai M, Li KL, Qian DJ, et al. Evaluation of left atrial function by speckle tracking echocardiography in patients with systemic lupus erythematosus. Lupus 2016; 25(5): 496-504.

[http://dx.doi.org/10.1177/0961203315619029] [PMID: 26657736]

[27] Briet M, Bozec E, Laurent S, et al. Arterial stiffness and enlargement in mild-to-moderate chronic kidney disease. Kidney Int 2006; 69(2): 350-7.

[http://dx.doi.org/10.1038/sj.ki.5000047] [PMID: 16408126]

[28] Hermans MM, Henry RM, Dekker JM, Nijpels G, Heine RJ,
Stehouwer CD. Albuminuria, but not estimated glomerular filtration rate, is associated with maladaptive arterial remodeling: the Hoorn Study. J Hypertens 2008; 26(4): 791-7.

[http://dx.doi.org/10.1097/HJH.0b013e3282f50066] [PMID: 18327090]

[29] Zalba G, Fortuño A, Díez J. Oxidative stress and atherosclerosis in early chronic kidney disease. Nephrol Dial Transplant 2006; 21(10): 2686-90.

[http://dx.doi.org/10.1093/ndt/gfl398] [PMID: 16861737]

[30] Visconti L, Cernaro V, Ricciardi CA, et al. Renal biopsy: Still a landmark for the nephrologist. World J Nephrol 2016; 5(4): 321-7. [http://dx.doi.org/10.5527/wjn.v5.i4.321] [PMID: 27458561]

[31] Castrejón I, Tani C, Jolly M, Huang A, Mosca M. Indices to assess patients with systemic lupus erythematosus in clinical trials, long-term observational studies, and clinical care. Clin Exp Rheumatol 2014; 32(5)(Suppl. 85): S-85-95. [PMID: 25365095]

[32] Petri M. Disease activity assessment in SLE: do we have the right instruments? Ann Rheum Dis 2007; 66(Suppl. 3): iii61-4. [http://dx.doi.org/10.1136/ard.2007.078477] [PMID: 17934099]

[33] Traynor J, Mactier R, Geddes CC, Fox JG. How to measure renal function in clinical practice. BMJ 2006; 333(7571): 733-7. [http://dx.doi.org/10.1136/bmj.38975.390370.7C] [PMID: 17023465]

[34] Schena FP, Selvaggi FP. Malattie dei reni e delle vie urinarie $\left(3^{\mathrm{a}}\right.$ edizione). New York, Milano: McGraw-Hill 2003; pp. 63-6.

[35] Zhang L, Zuo L, Wang F, et al. Cardiovascular disease in early stages of chronic kidney disease in a Chinese population. J Am Soc Nephrol 2006; 17(9): 2617-21

[http://dx.doi.org/10.1681/ASN.2006040402] [PMID: 16885404]

[36] Briasoulis A, Bakris GL. Chronic kidney disease as a coronary artery disease risk equivalent. Curr Cardiol Rep 2013; 15(3): 340 [http://dx.doi.org/10.1007/s11886-012-0340-4] [PMID: 23338722]

[37] Park M, Hsu CY, Li Y, et al. Associations between kidney function and subclinical cardiac abnormalities in CKD. J Am Soc Nephrol 2012; 23(10): 1725-34

[http://dx.doi.org/10.1681/ASN.2012020145] [PMID: 22935481]

[38] Foley RN, Parfrey PS, Harnett JD, et al. Clinical and echocardiographic disease in patients starting end-stage renal disease therapy. Kidney Int 1995; 47(1): 186-92. [http://dx.doi.org/10.1038/ki.1995.22] [PMID: 7731145]

[39] Feigenbaum H, Mastouri R, Sawada S. A practical approach to using strain echocardiography to evaluate the left ventricle. Circ J 2012; 76(7): 1550-5.

[http://dx.doi.org/10.1253/circj.CJ-12-0665] [PMID: 22789972]

[40] Piepoli MF, Hoes AW, Agewall S, et al. ESC Scientific Document Group. 2016 European Guidelines on cardiovascular disease prevention in clinical practice. Eur Heart J 2016; 37(29): 2315-81. [http://dx.doi.org/10.1093/eurheartj/ehw106] [PMID: 27222591]

[41] Geyer $\mathrm{H}$, Caracciolo $\mathrm{G}$, Abe $\mathrm{H}$, et al. Assessment of myocardial mechanics using speckle tracking echocardiography: Fundamentals and clinical applications. J Am Soc Echocardiogr 2010; 23(4): 351-69. [http://dx.doi.org/10.1016/j.echo.2010.02.015] [PMID: 20362924]

[42] Ayoub AM, Keddeas VW, Ali YA, El Okl RA. Subclinical lv dysfunction detection using speckle tracking echocardiography in hypertensive patients with preserved lv ejection fraction. Clin Med Insights Cardiol 2016; 10: 85-90.

[http://dx.doi.org/10.4137/CMC.S38407] [PMID: 27385916]

[43] Mizuguchi Y, Oishi Y, Miyoshi H, Iuchi A, Nagase N, Oki T. Concentric left ventricular hypertrophy brings deterioration of systolic longitudinal, circumferential, and radial myocardial deformation in hypertensive patients with preserved left ventricular pump function. J Cardiol 2010; 55(1): 23-33.

[http://dx.doi.org/10.1016/j.jjcc.2009.07.006] [PMID: 20122545]

[44] Liu YW, Tsai WC, Su CT, Lin CC, Chen JH. Evidence of left ventricular systolic dysfunction detected by automated function imaging in patients with heart failure and preserved left ventricular ejection fraction. J Card Fail 2009; 15(9): 782-9.

[http://dx.doi.org/10.1016/j.cardfail.2009.05.006] [PMID: 19879465]

[45] Ersbøll M, Valeur N, Mogensen UM, et al. Prediction of all-cause mortality and heart failure admissions from global left ventricular longitudinal strain in patients with acute myocardial infarction and preserved left ventricular ejection fraction. J Am Coll Cardiol 2013; 61(23): 2365-73.

[http://dx.doi.org/10.1016/j.jacc.2013.02.061] [PMID: 23563128]

[46] Saito M, Khan F, Stoklosa T, Iannaccone A, Negishi K, Marwick TH Prognostic implications of lv strain risk score in asymptomatic patients with hypertensive heart disease. JACC Cardiovasc Imaging 2016; 
9(8): 911-21.

[http://dx.doi.org/10.1016/j.jcmg.2015.09.027] [PMID: 27344417]

[47] Liu YW, Su CT, Huang YY, et al. Left ventricular systolic strain in chronic kidney disease and hemodialysis patients. Am J Nephrol 2011; 33(1): 84-90.

[http://dx.doi.org/10.1159/000322709] [PMID: 21178338]

[48] Krishnasamy R, Isbel NM, Hawley CM, et al. The association between left ventricular global longitudinal strain, renal impairment and allcause mortality. Nephrol Dial Transplant 2014; 29(6): 1218-25. [http://dx.doi.org/10.1093/ndt/gfu004] [PMID: 24516227]

[49] Schoenfeld SR, Kasturi S, Costenbader KH. The epidemiology of atherosclerotic cardiovascular disease among patients with SLE: A systematic review. Semin Arthritis Rheum 2013; 43(1): 77-95. [http://dx.doi.org/10.1016/j.semarthrit.2012.12.002]

[PMID: 23422269]

[50] Tektonidou MG, Wang Z, Ward MM. Brief report: Trends in hospitalizations due to acute coronary syndromes and stroke in patients with systemic lupus erythematosus, 1996 to 2012. Arthritis Rheumatol 2016; 68(11): 2680-5.

[http://dx.doi.org/10.1002/art.39758] [PMID: 27273732]

[51] Zeller CB, Appenzeller S. Cardiovascular disease in systemic lupus erythematosus: the role of traditional and lupus related risk factors. Curr Cardiol Rev 2008; 4(2): 116-22.

[http://dx.doi.org/10.2174/157340308784245775] [PMID: 19936286]

[52] Hak AE, Karlson EW, Feskanich D, Stampfer MJ, Costenbader KH. Systemic lupus erythematosus and the risk of cardiovascular disease: results from the nurses' health study. Arthritis Rheum 2009; 61(10): 1396-402.

[http://dx.doi.org/10.1002/art.24537] [PMID: 19790130]

[53] Lee T, Derebail VK, Kshirsagar AV, et al. Patients with primary membranous nephropathy are at high risk of cardiovascular events. Kidney Int 2016; 89(5): 1111-8

[http://dx.doi.org/10.1016/j.kint.2015.12.041] [PMID: 26924046]

[54] Betriu-Bars Á, Fernández-Giráldez E. Carotid ultrasound for the early diagnosis of atherosclerosis in chronic kidney disease. Nefrologia 2012; 32(1): 7-11. [PMID: 22293998]

[55] Briet M, Bozec E, Laurent S, et al. Arterial stiffness and enlargement in mild-to-moderate chronic kidney disease. Kidney Int 2006; 69(2): 350-7.

[http://dx.doi.org/10.1038/sj.ki.5000047] [PMID: 16408126]

[56] Schoenfeld SR, Kasturi S, Costenbader KH. The epidemiology of atherosclerotic cardiovascular disease among patients with SLE: A systematic review. Semin Arthritis Rheum 2013; 43(1): 77-95. [http://dx.doi.org/10.1016/j.semarthrit.2012.12.002] [PMID: 23422269]

[57] Roman MJ, Shanker BA, Davis A, et al. Prevalence and correlates of accelerated atherosclerosis in systemic lupus erythematosus. N Engl J Med 2003; 349(25): 2399-406.

[http://dx.doi.org/10.1056/NEJMoa035471] [PMID: 14681505]

[58] Holmqvist M, Simard JF, Asplund K, Arkema EV. Stroke in systemic lupus erythematosus: A meta-analysis of population-based cohort studies. RMD Open 2015; 1(1)e000168

[http://dx.doi.org/10.1136/rmdopen-2015-000168] [PMID: 26719816]

[59] Iannuzzi M, D'Angelillo A, Tortori A, et al. Carotid artery diameter and wall stiffness in proteinuric renal disease without severely reduced kidney function. J Clin Ultrasound 2016; 44(3): 175-81.

[http://dx.doi.org/10.1002/jcu.22292] [PMID: 26402850]

[60] Nikolic D, Banach M, Nikfar S, et al. Lipid and Blood Pressure MetaAnalysis Collaboration Group. A meta-analysis of the role of statins on renal outcomes in patients with chronic kidney disease. Is the duration of therapy important? Int J Cardiol 2013; 168(6): 5437-47. [http://dx.doi.org/10.1016/j.ijcard.2013.08.060] [PMID: 24016544]

[61] Barylski M, Nikfar S, Mikhailidis DP, et al. Lipid and Blood Pressure Meta-Analysis Collaboration Group. Statins decrease all-cause mortality only in CKD patients not requiring dialysis therapy-A metaanalysis of 11 randomized controlled trials involving 21,295 participants. Pharmacol Res 2013; 72: 35-44. [http://dx.doi.org/10.1016/j.phrs.2013.03.007] [PMID: 23542730]

62] Nikolic D, Nikfar S, Salari P, et al. Effects of statins on lipid profile in chronic kidney disease patients: a meta-analysis of randomized controlled trials. Curr Med Res Opin 2013; 29(5): 435-51.

[http://dx.doi.org/10.1185/03007995.2013.779237] [PMID: 23427811]

[63] Kostapanos MS, Liberopoulos EN, Elisaf MS. Statin pleiotropy against renal injury. J Cardiometab Syndr 2009; 4(1): E4-9. [http://dx.doi.org/10.1111/j.1559-4572.2008.00052.x]

[PMID: 19245508]

[64] Piepoli MF, Hoes AW, Agewall S, et al. ESC Scientific Document Group. 2016 European Guidelines on cardiovascular disease prevention in clinical practice: The Sixth Joint Task Force of the European Society of Cardiology and Other Societies on Cardiovascular Disease Prevention in Clinical Practice (constituted by representatives of 10 societies and by invited experts)Developed with the special contribution of the European Association for Cardiovascular Prevention \& Rehabilitation (EACPR). Eur Heart J 2016; 37(29): 2315-81.

[http://dx.doi.org/10.1093/eurheartj/ehw106] [PMID: 27222591]

[65] Hahn BH, McMahon M, Wilkinson A, et al. American College of Rheumatology Guidelines for Screening, Case Definition, Treatment and Management of Lupus Nephritis Arthritis Care Res (Hoboken) 2012; 64: 797-808.

[66] Mikhailidis DP, Athyros VG. Acute kidney injury: Short-term statin therapy for prevention of contrast-induced AKI. Nat Rev Nephrol 2014; 10(1): 8-9.

[http://dx.doi.org/10.1038/nrneph.2013.249] [PMID: 24217459]

[67] Katsiki N, Athyros VG, Karagiannis A, Mikhailidis DP. Contrastinduced nephropathy: An "all or none" phenomenon? Angiology 2015; 66(6): 508-13.

[http://dx.doi.org/10.1177/0003319714550309] [PMID: 25225196]

[68] Paraskevas KI, Mikhailidis DP. Contrast-induced acute kidney injury in patients undergoing carotid artery stenting: An underestimated issue. Angiology 2017; 68(9): 752-6.

[http://dx.doi.org/10.1177/0003319716668934] [PMID: 27645233]

[69] Ali-Hasan-Al-Saegh S, Mirhosseini SJ, Ghodratipour Z, et al. Strategies preventing contrast-induced nephropathy after coronary angiography: A comprehensive meta-analysis and systematic review of 125 randomized controlled trials. Angiology 2017; 68(5): 389-413. [http://dx.doi.org/10.1177/0003319716661445] [PMID: 27485363]

[70] Baltatzi M, Savopoulos Ch, Hatzitolios A. Role of angiotensin converting enzyme inhibitors and angiotensin receptor blockers in hypertension of chronic kidney disease and renoprotection. Study results. Hippokratia 2011; 15(Suppl. 1): 27-32. [PMID: 21897755]

[71] Piepoli MF, Hoes AW, Agewall S, et al. ESC Scientific Document Group. 2016 European Guidelines on cardiovascular disease prevention in clinical practice: The Sixth Joint Task Force of the European Society of Cardiology and Other Societies on Cardiovascular Disease Prevention in Clinical Practice (constituted by representatives of 10 societies and by invited experts)Developed with the special contribution of the European Association for Cardiovascular Prevention \& Rehabilitation (EACPR). Eur Heart J 2016; 37(29): 2315-81.

[http://dx.doi.org/10.1093/eurheartj/ehw106] [PMID: 27222591]

[72] Floege J. Primary glomerulonephritis: A review of important recent discoveries. Kidney Res Clin Pract 2013; 32(3): 103-10.

[http://dx.doi.org/10.1016/j.krcp.2013.06.004] [PMID: 26877924]

[73] Dooley MA, Ginzler EM. Newer therapeutic approaches for systemic lupus erythematosus: Immunosuppressive agents. Rheum Dis Clin North Am 2006; 32(1): 91-102, ix.

[http://dx.doi.org/10.1016/j.rdc.2005.11.003] [PMID: 16504823]

[74] Houssiau FA, Ginzler EM. Current treatment of lupus nephritis. Lupus 2008; 17(5): 426-30

[http://dx.doi.org/10.1177/0961203308090029] [PMID: 18490421]

[75] Liu YC, Chun J. Prospects for precision medicine in glomerulonephritis treatment. Can J Kidney Health Dis 2018. [http://dx.doi.org/10.1177/2054358117753617]

\section{(C) 2019 Atteritano et al.}

This is an open access article distributed under the terms of the Creative Commons Attribution 4.0 International Public License (CC-BY 4.0), a copy of which is available at: (https://creativecommons.org/licenses/by/4.0/legalcode). This license permits unrestricted use, distribution, and reproduction in any medium, provided the original author and source are credited. 